\title{
Energy efficiency maximization for full duplex MIMO cloud radio access networks
}

\author{
Tien Ngoc Ha ${ }^{1,2}$, Xuan-Xinh Nguyen ${ }^{1,2}$, Ha Hoang Kha ${ }^{1,2, *}$
}

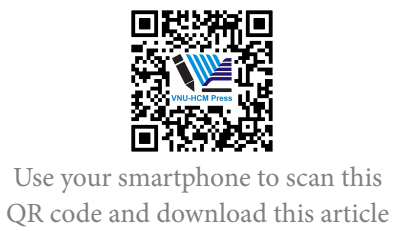

${ }^{1}$ Faculty of Electrical \& Electronics Engineering, Ho Chi Minh City University of Technology (HCMUT), 268 Ly Thuong Kiet Street, District 10, Ho Chi Minh City, Vietnam

${ }^{2}$ Vietnam National University Ho Chi Minh City, Linh Trung Ward, Thu Duc District, Ho Chi Minh City, Vietnam

Correspondence

Ha Hoang Kha, Faculty of Electrical \& Electronics Engineering, Ho Chi Minh City University of Technology (HCMUT), 268 Ly Thuong Kiet Street, District 10, Ho Chi Minh City, Vietnam

Vietnam National University Ho Chi Minh City, Linh Trung Ward, Thu Duc District, Ho Chi Minh City, Vietnam

Email: hhkha@hcmut.edu.vn

History

- Received: 17-3-2020

- Accepted: 4-12-2020

- Published: 20-12-2020

DOI :10.32508/stdjet.v3i3.685

\section{Check for updates}

\section{Copyright}

(c) VNU-HCM Press. This is an openaccess article distributed under the terms of the Creative Commons Attribution 4.0 International license.

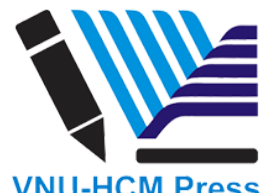

\begin{abstract}
This paper studies the energy efficiency (EE) in full-duplex (FD) multiple-input multiple-output (MIMO) cloud radio access networks (CRANs). A cloud control unit (CU) transfers information signals with multiple downlink (DL) and uplink (UL) users through FD radio units (RUs) by limited capacity FH links. In DL transmission, the signals intended to the DL users are centrally processed at the $\mathrm{CU}$ and, then, compressed to transfer to the RUs before they are forwarded to the DL users. On the other hand, the signals from the UL users to the RUs are compressed and forwarded to the CU for signal detection processing. Thus, the precoding designs and compression strategies for the $\mathrm{UL}$ and $\mathrm{DL}$ transmission are critical for the system performance. The conventional methods commonly focus on maximizing the spectral efficiency (SE) in the networks. Although the SE maximization based methods can offer the superior SE performance, they can result in the inefficient usage of the energy in the networks. Thus, this paper focuses on the joint design of the precoders and quantization covariance matrices to maximize the EE. The EE maximization problem is formulated as an optimization problem of the precoders and quantization covariance matrices subject to the transmit power constraints at each RU, each user and the limited capacity of FH links. To deal with the non-convexity of the formulated design problem, we exploit a successive convex approximation (SCA) method to derive the concave lower bound function of the sum rate and a convex upper bound of capacity functions of FH links. Then, the Dinkelbach approach is exploited to derive an efficient iterative algorithm (IA) guaranteeing convergence. Numerical results are given to demonstrate the EE performance of the proposed algorithm.
\end{abstract}

Key words: Full-duplex, CRAN, precoding design, energy efficiency

\section{INTRODUCTION}

Over the past years, the explosive surge in the amount of mobile data has resulted in the challenging requirements of advanced wireless communication possessing techniques to obtain not only higher achievable data rates but also lower power consumption ${ }^{1}$. Cloud radio access networks (CRANs) are a modern architecture for the next generation of mobile wireless systems. CRANs rely on the leverage of a baseband processing with central unit (CU) that leads to not only the effective joint transmission but also the replacement high-cost high-power base stations with the low-cost low-power radio units (RUs). As such, CRAN approaches can both enhance spectrum efficiency and reduce power consumption. CRANs have thus attracted significant investigations, see, e.g., ${ }^{2}$ and references therein.

On the other hand, multi-antenna techniques have also been recognized as the efficient transmission methods because they provide more degrees of freedom enable to steer signal's directions to the desired users which are called beamforming or precoding techniques. Hence, they are able to simul- taneously transfer more than one data streams over a specific resource, that can thus potentially achieve greater data rates. On this view, CRAN systems with multiple antennas have studied extensively as a potential approach to improve spectral efficiency (SE). There are studies on various implementation scenarios for CRAN systems including either only multiantenna at RUs and single-antenna user equipments (UEs) namely as multiple-input single-output CRAN $(\text { MISO CRAN })^{3-7}$, or multi-antenna at both RUs and UEs, referred as multiple-input multiple-output CRAN (MIMO CRAN) ${ }^{8-10}$. Reference ${ }^{3}$ addressed the problem of concurrently optimizing both sum rate (SR) and total transmit power (TP) by using a multiobjective framework. They investigated on the algorithm for jointly beamforming, turning RUs on/off, and associating UEs to RU groups. Moreover, the authors in ${ }^{4}$ first integrated nonorthogonal multiple access techniques into downlink MISO CRAN systems and, then tackled the problem of the beamforming design to maximize minimum data rate under TP and limited fronthaul $(\mathrm{FH})$ rate constraints. Additionally, the work in ${ }^{5}$ proposed a wireless powered MISO 
CRAN in which UEs support information decoding and energy harvesting in downlink (DL) periods and, then, they transmit their own signals by using harvested energy in uplink (UL) phases. The minimum UL rate maximization problem then was addressed under minimum DL rate, TP, and FH rate constraints. Alternatively, to further improve the SE, the hybrid digital-analog beamforming ${ }^{6}$ and rate-splitting multiple access scheme ${ }^{7}$ were considered in DL MISO CRAN systems. In addition, by considering a MIMO CRAN system, Park et. al. proposed SR maximization algorithms by jointly designing precoding and FH compressing for either DL or UL CRAN systems in $^{8}$ and ${ }^{9}$, respectively. Then, reference ${ }^{10}$ investigated on a multi-cluster DL MIMO CRAN system in which the effective design is then studied by taking intercluster interference into account.

Along with these two emerging approaches, i.e., CRANs and multi-antenna, full-duplex (FD) transmission is also a powerful technique to achieve the SE improvement. Thanks to the fact that the selfinterference (SI) caused by FD transmission mode can be significantly suppressed, FD communication can efficiently support both transmission and reception in the same frequency and time resources. Thus, FD schemes can potentially double channel capacity compared to traditional half-duplex (HD) counterparts $^{11-15}$. Recently, the combination of FD transmission into CRAN systems has drawn considerable attention and conducted in the works ${ }^{16-21}$. Reference $^{16}$ studied the system capacity in a basic FD CRANs and demonstrated that the system SE of FD mode is superior to that of both HD mode and single cellular design approach. The authors in ${ }^{17}$ first developed wireless power transfer techniques for FD MISO CRAN systems and, then, proposed an optimal approach for minimizing TP with the constraints of both UL, DL rate qualities and minimum amount of harvested energy. In ${ }^{18}$, the authors aimed at optimizing the SR of FD MIMO CRAN systems under the constraints of TP and maximum supported rates over FH links. Alternatively, the work in ${ }^{19}$ exploited the relationship between the weighted minimum mean squared error (MMSE) problem and weighted SR problem in order to develop a low computational complexity iterative algorithm (IA) for maximizing the system SE. The computing time is then reduced as compared to the method in ${ }^{18}$. Additionally, the joint design of transmit beamformers, power allocation, FH compression ratio and RU selection was investigated to either minimize TP under quality-ofservice (QoS) constraints in ${ }^{20}$ or maximize the DL capacity under UL QoS constraints in ${ }^{21}$.
However, the transmit strategies which are designed merely on the system data rate as mentioned above can result in the negative impacts on the system energy efficiency $(\mathrm{EE})^{22-24}$. Hence, the transmission approaches with EE have been taken into consideration recently for CRAN systems ${ }^{25-32}$. Reference ${ }^{25}$ studied the joint design of beamforming and RU selection to minimize TP under the constraints on quality of each user's links. The authors in ${ }^{26}$ considered the power minimization problem along with minimum data rate requirements. They developed the optimal solution for both data sharing and data compressing MISO CRANs. Furthermore, the work in ${ }^{27}$ investigated the EE problem in DL MIMO CRANs by jointly designing precoding matrices and turning on/off RUs. The results shown that the system EE is significantly enhanced as compared to some benchmark schemes. In addition, concerning a DL contentcentric MIMO CRANs, ${ }^{28}$ addressed both SE and EE problems by successive convex quadratic programming for jointly designing user association, RU activation, data rate allocation, and precoding matrices. In $^{29}$, the EE of DL MISO CRAN systems was maximized by optimizing both beamformers and RUUE grouping. Similarly, the EE of downlink MISO CRANs was maximized by jointly designing the transmit beamforming, RU selection, and RU-UE association with difference of convex (D.C.) programming in $^{30}$ and sequence of second order cone programming in ${ }^{31}$. More recently, the EE optimization problem (OP) for FD MISO CRAN based data sharing system was tackled in ${ }^{32}$, however, the $\mathrm{FH}$ rate constraints was ignored.

Motivated from above discussions, this paper is concerned with a FD MIMO CRAN system in which multiple-antenna DL and UL users communicate with a cloud CU through FD multiple-antenna RUs. We aim at designing the optimal precoder and the quantization covariance matrices to maximize the system EE under TP and FH link rate constraints. The design problem is mathematically expressed as a constrained OP which is highly non-convex in design variables. The challenges in solving the $\mathrm{OP}$ are due to not only a fraction form and non-concavity of the objective function but also non-convexity in $\mathrm{FH}$ rate constraints. Thus, the D.C. programming is used to obtain bounds of the achievable SR and FH rate. Then, the Dinkelbach method is applied to develop an efficient IA with a convex OP solved in each iteration. The numerical simulations are conducted to verify the convergence of our IA and to examine the EE performance of the proposed EE optimization. 
The remainder of the paper is organized as follows. Sec. II describes the system model of FD MIMO CRANs and, then, formulates the design of precoding and quantization noise covariance matrices as an OP. Then, an IA to seek the optimal matrices is presented in Sec. III. Numerical simulation results are given in Sec. IV. Finally, the conclusions are presented in Sec. $\mathrm{V}$.

Notations: Boldface upper (lower) case letters denote matrices (vectors), An identity matrix with appropriate dimension is presented by $\mathrm{I} . \mathrm{X}^{\mathrm{T}}, \mathrm{X}^{\mathrm{H}},\langle\mathrm{X}\rangle$ and $|\mathrm{X}|$ are the transpose, Hermitian transpose, trace and determinant of matrix $\mathrm{X} . \mathrm{X} \succeq 0$ denotes a positive semidefinite matrix. A complex Gaussian random vector $\mathbf{x}$ with mean $\overline{\mathbf{x}}$ and covariance $\mathrm{R}_{\mathrm{X}}$ is represented by $\mathrm{x} \sim \mathrm{CN}\left(\overline{\mathrm{x}} ; \mathrm{R}_{\mathrm{x}}\right)$.

\section{SYSTEM MODEL AND PROBLEM FORMULATION}

Consider a FD MIMO CRAN model similar to that in ${ }^{18,19}$ in which $K_{R}$ FD RUs are connected to a CU via the FH links, as shown in Figure 1. All the RUs simultaneously serve a set of $K_{U L}$ UL and $K_{D L}$ DL users via radio access links. Denote $R U_{k}, D L U_{k}$ and $U L U_{k}$ as the $k$ th FD RU, $k$ th DLU and $k$ th ULU, respectively. We also denote $S^{U L}, S^{D L}$ and $S^{R U}$ as the set of all ULUs, DLUs, and RUs, respectively. $R U_{k}$ has $M_{k}$ transmit antennas (TAs) and $N_{k}$ receive antennas (RAs). Thus, $M^{D L}=\sum_{k=1}^{K_{R}} M_{k}$ and $N^{D L}=\sum_{k=1}^{K_{R}} M_{k}$ are total TAs and RAs at the RUs. Also, $T_{k}$ and $R_{k}$ are the number of antennas at $U L U_{k}$ and $D L U_{k}$. To reliably detect the signals, it is assumed that the sum of data streams of all UL users should be less than or equal to the total number of the TAs at the UL users and the sum of RAs of all RUs. Assume that the ideal channel state information is available at the RUs and users ${ }^{33}$. In the DL transmission, denote the data symbol $s_{k}^{D L} \in$ $\mathbb{C}^{d_{k}^{D L} \times 1}$ with $s_{k}^{D L} \sim \mathrm{CN}(0, \mathrm{I})$ as $d_{k}^{D L}$ of data streams intended to $D L U_{k}, k \in S^{D L}$. The CU generates a transmitted baseband signals $\widetilde{x}_{i}^{D L} \in \mathbb{C}^{M_{i} \times 1}$ for $R U_{i}$ as

$$
\widetilde{x}_{i}^{D L}=\sum_{k=1}^{K_{D L}} \mathrm{~F}_{k i}^{D L} \mathrm{~s}_{k}^{D L}
$$

where $\mathrm{F}_{k i}^{D L} \in \mathbb{C}^{M_{i} \times d_{k}^{D L}}$ denotes the precoding matrix of the $k$-th DLU in $R U_{i}$. By defining all the signals generated at the $\mathrm{CU}$ as $\widetilde{x}^{D L}=\left[\left(\widetilde{x}_{1}^{D L}\right)^{T}, \ldots,\left(\widetilde{x}_{R}^{D L}\right)^{T}\right] \in$ $\mathbb{C}^{M^{D L} \times 1}$, we have

$$
\widetilde{\mathrm{x}}^{D L}=\sum_{k=1}^{K_{D L}} \mathrm{~F}_{k}^{D L} \mathrm{~s}_{k}^{D L},
$$

where $\mathrm{F}_{k i}^{D L} \triangleq\left[\left(\mathrm{F}_{k l}^{D L}\right)^{H},\left(\mathrm{~F}_{k 2}^{D L}\right)^{H}, \ldots,\left(\mathrm{F}_{k k_{R}}^{D L}\right)^{H}\right]^{H} \in$ $\mathbb{C}^{M_{i} \times d_{k}^{D L}} \quad$ From (1) and (2), we can obtain $\widetilde{\mathrm{x}}_{i}^{D L}=\gamma_{i}^{H} \widetilde{\mathrm{x}}^{D L}$ to $R U_{i}$, where $\gamma_{i}=$

$$
\left[0_{\sum_{k=1}^{T} M_{k} \times M_{i}}^{T}, I_{M_{i} \times M_{i}}^{T}, 0_{\sum_{k=i+1}^{T} K_{k}}^{K_{k} \times M_{i}}\right]^{T} \text {. }
$$

Before transferring the signals to the corresponding $\mathrm{RU}$ on the FH links, the baseband signal $\widetilde{\mathrm{x}}_{i}^{D L}$ is first compressed by quantizing. Then, the received signal at $R U_{i}$ is written as

$$
x_{i}^{D L}=\widetilde{\mathrm{x}}_{i}^{D L}+q_{i}^{D L}, i \in S^{R U},
$$

where $\mathrm{q}_{i}^{D L} \sim \mathrm{CN}\left(0, \Xi_{i}^{D L}\right)$ is the quantization noise associated with the signals to $R U_{i}$ in the DL channel and $\Xi_{i}^{D L} \in \mathbb{C}^{M_{k} \times M_{k}}$ is the covariance matrix of downlink quantization noise. From (3), the DL FH rate at $R U_{i}$ is imposed by the following constraint ${ }^{18,19}$

$$
\begin{aligned}
& \log \left|\gamma_{i}^{H} \sum_{k=1}^{K_{D L}} \mathrm{~F}_{k}^{D L}\left(\mathrm{~F}_{k}^{D L}\right)^{H} \gamma_{i}+\Xi_{i}^{D L}\right| \\
& -\log \left|\Xi_{i}^{D L}\right| \leq C_{i}^{D L}, i \in S^{R U}
\end{aligned}
$$

where $C_{i}^{D L}$ is the maximum DL FH rate associated with $R U_{i}$. It is worth noting that $R U_{i}$ will transmit signal $x_{i}^{D L}$ in (3) to the DLUs. In light of (1), (2), (3), the TP constraint at $R U_{i}$ is given by

$\left\langle\gamma_{i}^{H} \sum_{k=1}^{K_{D L}} \mathrm{~F}_{k}^{D L}\left(\mathrm{~F}_{k}^{D L}\right)^{H} \gamma_{i}+\Xi_{k}^{D L}\right\rangle \leq P_{i}^{D L}, i \in S^{R U}$

where $P_{i}^{D L}$ is the maximum allowable TP at $R U_{i}$. Denote by $H_{k i}^{D L} \in \mathbb{C}^{R_{k} \times M_{i}}$ the flat-fading channel matrix from $R U_{i}$ to $D L U_{k}$, by $H_{k}^{D L}=\left[H_{k 1}^{D L}, \ldots, H_{k K_{R}}^{D L}\right] \in$ $\mathbb{C}^{R_{k} \times M_{i}}$ the channel matrix from all RUs to $D L U_{k}$ and $H_{k l}^{D U} \in \mathbb{C}^{R_{k} \times R_{l}}$ the CCI channel from $U L U_{k}$ to $D L U_{k}$. Before forwarding to the DLUs, the compressed signal from the CU is decompressed by the RUs. Hence, the received signal at $D L U_{k}$ is

$$
\begin{aligned}
& y_{k}^{D L}=\sum_{i=1}^{K_{R}} H_{k i}^{D L} x_{i}^{D L}+\sum_{l=1}^{K_{U L}} H_{k l}^{D U} x_{l}^{U L}+n_{k}^{D L} \\
& =H_{k}^{D L} x^{D L}+\sum_{l=1}^{K_{U L}} H_{k l}^{D U} x_{l}^{U L}+n_{k}^{D L}, k \in S^{D L},
\end{aligned}
$$

where we have defined $x^{D L}=$ $\left[\left(x_{1}^{D L}\right)^{T}, \ldots,\left(x_{K_{R}}^{D L}\right)^{T}\right] \in \mathbb{C}^{M_{D L} \times 1}$ and $x_{l}^{U L} \in \mathbb{C}^{T_{l} \times 1}$ is the transmit signal vector of $U L U_{l}$. Moreover, $n_{k}^{D L} \sim C N\left(0, \sigma_{D L}^{2} I_{R_{K}}\right)$ is additive white Gaussian noise (AWGN) at $D L U_{k}$. From (6), the achievable data rate $R_{k}^{D L}$ at $D L U_{k}$, is

$$
\begin{aligned}
& R_{K}^{D L}=\log \left|I_{R_{k}}+H_{k}^{D L} F_{k}^{D L}\left(H_{k}^{D L} F_{k}^{D L}\right)^{H} \triangle_{k, D L}^{-1}\right| \\
& =\log \left|H_{k}^{D L} F_{k}^{D L}\left(H_{k}^{D L} F_{k}^{D L}\right)^{H} \triangle_{k, D L}\right|-\log \left|\triangle_{k, D L}\right|
\end{aligned}
$$

where $\triangle_{k, D L}$ is the interference-plus noise covariance matrix at $D L U_{k}$ and is defined as

$$
\begin{aligned}
& \triangle_{k, D L}= \\
& H_{k}^{D L}\left(\sum_{l=1, l \neq k}^{K_{D L}} F_{l}^{D L}\left(F_{l}^{D L}\right)^{H}+\widetilde{\Xi}^{D L}\right)\left(H_{k}^{D L}\right)^{H} \\
& +\sum_{l=1}^{K_{U L}} H_{k l}^{D U} F_{l}^{U L}\left(H_{k l}^{D U} F_{l}^{U L}\right)^{H}+\sigma_{D L}^{2} I_{R_{k}},
\end{aligned}
$$

where $\widetilde{\Xi}^{D L}=\operatorname{diag}\left\{\Xi_{1}^{D L}, \ldots, \Xi_{K_{R}}^{D L}\right\}$. 


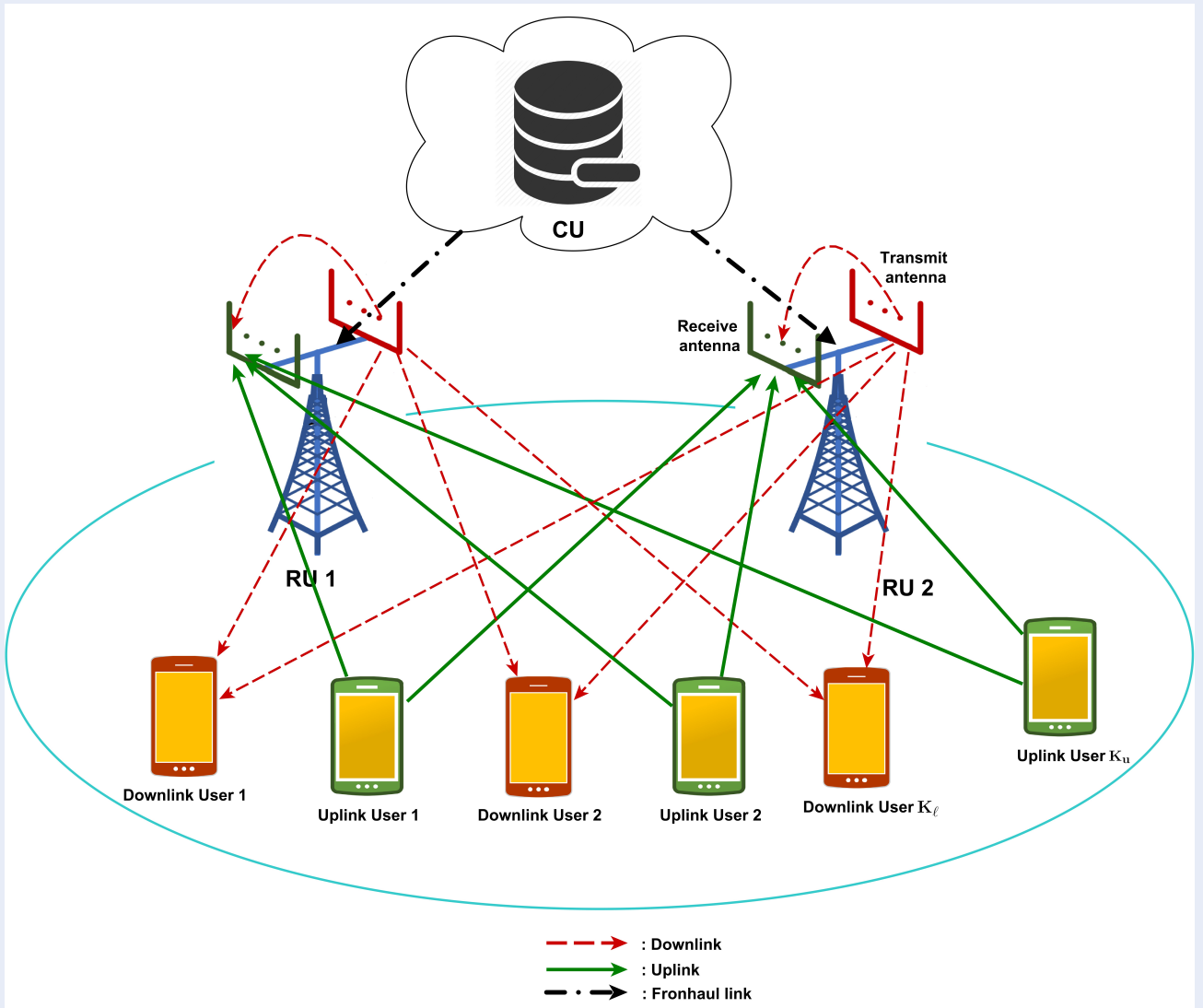

Figure 1: A system model of the FD CRAN with multiple MIMO users.

Concerning the UL transmission, denote $H_{i k}^{U L} \in$ $\mathbb{C}^{N_{i} \times T_{k}}$ as the channel matrix from $U L U_{k}$ to $R U_{i}$, and $H_{i j}^{U D} \in \mathbb{C}^{N_{i} \times M_{j}}$ represents the residual SI channel matrix from $R U_{j}$ to $R U_{i}$. Then, in the UL channel, the received signal $y_{i}^{U L}$ at $R U_{i}$ is

$$
\begin{aligned}
& y_{i}^{U L}=\sum_{k=1}^{K_{U L}} H_{i k}^{U L} F_{k}^{U L} s_{k}^{U L} \\
& +\sum_{j=1}^{K_{R}} H_{i j}^{U D} x_{j}^{D L}+n_{i}^{U L}, i \in S^{R U},
\end{aligned}
$$

where $F_{k}^{U L} \in \mathbb{C}^{T_{k} \times d_{k}^{U L}}$ denotes the precoding matrix for the data symbol $s_{k}^{U L} \in \mathbb{C}^{d_{k}^{U L} \times 1}$ of $U L U_{k}$ with $s_{k}^{U L} \sim C N\left(0, I_{d_{k}^{U L}}\right), d_{k}^{U L}$ is the number of data streams and the vector $n_{i}^{U L} \sim C N\left(0, \sigma_{U L}^{2} I_{N_{i}}\right)$ is AWGN at $R U_{i}$. The transmission of $U L U_{k}$ is subjected to the TP constraint $P_{k}^{U L}$ as

$$
\left\langle F_{k}^{U L}\left(F_{k}^{U L}\right)^{H}\right\rangle \leq P_{k}^{U L}, k \in S^{U L} .
$$

After receiving the signal from (9), $R U_{i}$ then compresses it and sends to the CU. Thus, the received signal at the $\mathrm{CU}$ is given by

$$
\tilde{y}_{i}^{U L}=y_{i}^{U L}+q_{i}^{U L}, i \in S^{R U},
$$

where $q_{i}^{U L} \sim C N\left(0, \Xi_{i}^{U L}\right)$ is the quantization noise at the $R U_{i}$ and $\Xi_{i}^{U L} \in \mathbb{C}^{N_{k} \times N_{k}}$ represents the covariance matrix of uplink quantization noise. From (11), the $\mathrm{CU}$ can retrieve the signal from $R U_{i}$ if the UL FH rate is subjected to ${ }^{18,19}$

$\log \left|\phi_{i}^{U L}+\Xi_{i}^{U L}\right|-\log \left|\Xi_{i}^{U L}\right| \leq C_{i}^{U L}, i \in S^{R U}$,

where $C_{i}^{U L}$ represents the UL FH rate constraint at the $R U_{i}$, and

$$
\begin{aligned}
& \phi_{i}^{U L}=\sum_{k=1}^{K_{U L}} H_{i k}^{U L} F_{k}^{U L}\left(H_{i k}^{U L} F_{k}^{U L}\right)^{H}+\sigma_{U L}^{2} I_{N_{i}} \\
& +\widetilde{H}_{i}^{U D}\left(\sum_{k=1}^{K_{D L}} F_{k}^{D L}\left(F_{k}^{D L}\right)^{H}+\widetilde{\Xi}^{D L}\right)\left(\widetilde{H}_{i}^{U D}\right)^{H}
\end{aligned}
$$

is the covariance matrix of the received signal $y_{i}^{U L}$. Here, we have defined $\widetilde{H}_{i}^{U D}=\left[H_{i 1}^{U D}, \ldots, H_{i K_{R}}^{U D}\right]$. At the CU, the signals from RUs are first stacked as $\widetilde{y}^{U L}=$ $\left[\left(\widetilde{y}_{1}^{U L}\right)^{T}, \ldots,\left(\widetilde{y}_{K_{R}}^{U L}\right)^{T}\right]^{T}$, and then the CU applies the linear MMSE decoding ${ }^{34}$. Therefore, the achievable rate for $U L U_{k}$ is

$$
\begin{aligned}
& R_{K}^{U L}=\log \left|I_{N^{U L}}+H_{k}^{D L} F_{k}^{D L}\left(H_{k}^{D L} F_{k}^{D L}\right)^{H} \triangle_{k, D L}^{-1}\right| \\
& =\log \left|H_{k}^{D L} F_{k}^{D L}\left(H_{k}^{D L} F_{k}^{D L}\right)^{H}+\triangle_{k, D L}\right|-\log \left|\triangle_{k, D L}\right|,
\end{aligned}
$$


where

$$
\begin{aligned}
& \triangle_{k, U L}=\sum_{l=1, l \neq k}^{K_{U L}} H_{l}^{U L} F_{l}^{U L}\left(H_{l}^{U L} F_{l}^{U L}\right)^{H}+ \\
& H^{U D}\left(\sum_{l=1, l \neq k}^{K_{D L}} F_{l}^{D L}\left(F_{l}^{D L}\right)^{H}+\widetilde{\Xi}^{D L}\right)\left(H^{U D}\right)^{H} \\
& +\widetilde{\Xi}^{U L}+\sigma_{U L}^{2} I_{N^{U L}}
\end{aligned}
$$

is the interference-plus-noise covariance matrix, and $\widetilde{\Xi}^{D L}=\operatorname{diag}\left\{\widetilde{\Xi}_{1}^{U L}, \quad \ldots, \quad \widetilde{\Xi}_{K_{R}}^{U L}\right\}$. Here, $\quad H_{k}^{U L}=\left[\left(H_{1 k}^{U L}\right)^{T}, \ldots,\left(H_{K_{R} k}^{U L}\right)^{T}\right] \quad$ and $H^{U D}=\left[H_{1}^{U D}, \ldots, H_{K_{R}}^{U D}\right]$, where $H_{j}^{U D}=$ $\left[\left(H_{1 j}^{U D}\right)^{T}, \ldots,\left(H_{K_{R} k}^{U D}\right)^{T}\right]$. Different from the previous work $^{19}$ which maximizes the SE, this paper focuses on the system EE. The system EE is defined as the ratio of the total SR to the total power consumption and computed by

$$
E E=\frac{\sum_{k=1}^{K_{D L}} R_{D L}+\sum_{k=1}^{K_{U L}} R_{k}^{U L}}{P}
$$

where $\quad P=\sum_{i=1}^{K_{R}}\left\langle\gamma_{i}^{H} \sum_{i=1}^{K_{D L}} F_{k}^{D L}\left(F_{k}^{D L}\right)^{H} \gamma_{i}+\right.$ $\left.\Xi_{i}^{D L}\right\rangle+\sum_{k=1}^{K_{U L}}\left\langle F_{k}^{U L}\left(F_{k}^{U L}\right)^{H} \gamma_{i}\right.$

$\left.\Xi_{i}^{D L}\right\rangle+\left(K_{D L}+K_{U L}\right) P_{U E}+K_{R} P_{R U}$ is total system power consumed by all the RUs and UEs ${ }^{35}$. Here, $P_{U E}$ and $P_{R U}$ are the circuit power consumed by a user device and RU, respectively. We assume that circuit power consumed by UEs is same, i.e. $P_{U E_{i}}=P_{U E}$, and also for the RUs. Our paper jointly optimizes the precoding and quantization noise covariance matrices to maximize the $\mathrm{EE}$ of the FD CRAN system subject to TP constraints in (5) and (10), and FH rate constraints in (4) and (12). Therefore, the design problem is mathematically formulated as

$$
\max _{\{\mathrm{F}, \Xi\}}=\frac{\sum_{k=1}^{K_{D L}} R_{k}^{D L}+\sum_{k=1}^{K_{U L}} R_{k}^{U L}}{P}
$$

$$
\text { s.t. (4), (5), (10), (12) }
$$

$$
\Xi_{i}^{X} \succeq 0, i \in S^{R U}, X \in\{U L, D L\} .
$$

The sets of optimization variables are $F \square \triangleq\left\{F_{k}^{X}: \forall k \in S^{X}, X \in\{U L, D L\}\right\} \quad$ and $\Xi \triangleq\left\{\Xi_{k}^{X}: \forall i \in S^{R U}, X \in\{U L, D L\}\right\}$. It can be shown that problem (17) is not a convex problem due to the non-convex fractional form of the objective function and non-convex constraints in (4), (12). Therefore, it is mathematically difficult to solve problem (17) directly. In next section, we will develop an IA based on sequential convex approximation and Dinkelbach approaches to make problem (17) amenable.

\section{METHODOLOGY}

In this section, we will recast problem (17) as a con5) vex programming so that it can be efficiently solved by convex solvers. Firstly, to facilitate the nonlinearity of the OP, we define $Q_{k}^{X}=F_{k}^{X}\left(F_{k}^{X}\right)^{H}, k \in S^{X}, x \in$ $\{U L, D L\}$. The FH rate constraints in (4) and (12) can be respectively expressed as

$$
\begin{aligned}
& \log \left|\gamma_{i}^{H} \sum_{k=1}^{K_{D L}} Q_{k}^{D L} \gamma_{i}+\Xi_{i}^{D L}\right| \\
& -\log \left|\Xi_{i}^{D L}\right| \leq C_{i}^{D L}, i \in S^{R U}
\end{aligned}
$$

and

$\log \left|\phi_{i}^{U L}+\Xi_{i}^{U L}\right|-\log \left|\Xi_{i}^{U L}\right| \leq C_{i}^{U L}, i \in S^{R U}$,

where

$$
\begin{aligned}
& \phi_{i}^{U L}=\sum_{k=1}^{K_{U L}} H_{i k}^{U L} Q_{k}^{U L}\left(H_{i k}^{U L}\right)^{H}+\sigma_{U L}^{2} I_{N_{i}} \\
& +\widetilde{H}_{i}^{U D}\left(\sum_{k=1}^{K_{D L}} Q_{k}^{D L}+\widetilde{\Xi}^{D L}\right)\left(\widetilde{H}_{i}^{U D}\right)^{H} .
\end{aligned}
$$

Then the achievable downlink rate in (7) can also be written as

$$
\begin{aligned}
R_{K}^{D L}= & \log \left|H_{k}^{D L} Q_{k}^{D L}\left(H_{k}^{D L}\right)^{H}+\triangle_{k, D L}\right| \\
& -\log \left|\triangle_{k, D L}\right|
\end{aligned}
$$

where

$$
\begin{aligned}
& \triangle_{k, D L}= \\
& H_{k}^{D L}\left(\sum_{l=1, l \neq k}^{K_{D L}} Q_{l}^{D L}+\widetilde{\Xi}^{D L}\right)\left(H_{k}^{D L}\right)^{H} \\
& +\sum_{l=1}^{K_{U L}} H_{k l}^{D U} Q_{l}^{U L}\left(H_{k l}^{D U}\right)^{H}+\sigma_{D L}^{2} I_{R_{k}},
\end{aligned}
$$

Similarly, the achievable uplink rate in (14) can be written as

$$
\begin{aligned}
R_{K}^{U L}= & \log \left|H_{k}^{U L} Q_{k}^{U L}\left(H_{k}^{U L}\right)^{H} \triangle_{k, U L}\right| \\
& -\log \left|\triangle_{k, U L}\right|,
\end{aligned}
$$

where

$$
\begin{aligned}
& \triangle_{k, U L}=\sum_{l=1, l \neq k}^{K_{U L}} H_{l}^{U L} Q_{l}^{U L}\left(H_{l}^{U L}\right)^{H}+ \\
& H^{U D}\left(\sum_{l=1}^{K_{D L}} Q_{l}^{D L}+\widetilde{\Xi}^{D L}\right)\left(H^{U D}\right)^{H} \\
& +\widetilde{\Xi}^{U L}+\sigma_{U L}^{2} I_{N^{U L}}
\end{aligned}
$$

On the other hand, the TP of RUs (5) and uplink users (10) also can be rewritten respectively as

$$
\left\langle\gamma_{i}^{H} \sum_{k=1}^{K_{D L}} Q_{k}^{D L} \gamma_{i}+\Xi_{k}^{D L}\right\rangle \leq P_{i}^{D L}, i \in S^{R U},
$$

$$
\left\langle Q_{k}^{U L}\right\rangle \leq P_{k}^{U L}, k \in S^{U L} .
$$

Then, the design of EE maximization is equivalently formulated as

$$
\max _{\{Q, \Xi\}}=\frac{\sum_{k=1}^{K_{D L}} R_{k}^{D L}+\sum_{k=1}^{K_{U L}} R_{k}^{U L}}{P}
$$

$$
\text { s.t. (18), (19), (25), (26) }
$$




$$
\begin{aligned}
& \Xi_{i}^{X} \succeq 0, i \in S^{R U}, X \in\{U L, D L\} . \\
& Q_{i}^{X} \succeq 0, i \in S^{R U}, X \in\{U L, D L\} .
\end{aligned}
$$

here $Q \triangleq\left\{Q_{k}^{X}: \forall k \in S^{X}, X \in\{U L, D L\}\right\}$ is the optimization variables.

Next, we approximate the objective function (27a) and constraints (18), (19) using the D.C. approximation and then use the Dinkelbach method. The D.C. procedure in $15,24,36$ is used to deal with the nonconvexity of the achievable rate function. Due to the fact that $\nabla_{x} \log |\mathrm{I}+\mathrm{X}|=(\mathrm{I}+\mathrm{X})^{-1}$, by applying the first-order Taylor approximation at $\mathrm{X}_{0}$, we have an inequality $\log |\mathrm{I}+\mathrm{X}| \leq \log \left|\mathrm{I}+\mathrm{X}_{0}\right|+\left\langle\left(\mathrm{I}+\mathrm{X}_{0}\right)^{-1}(\mathrm{X}-\right.$ $\left.\left.\mathrm{X}_{0}\right)\right\rangle$. Therefore, given feasible points $Q^{(n)}$ at iteration $n$, the rate functions $\widetilde{R}_{k}^{D L}$ and $\widetilde{R}_{k}^{U L}$ are respectively defined by

$$
\begin{aligned}
& \widetilde{R}_{k}^{D L}=\log \left|H_{k}^{D L} Q_{k}^{D L}\left(H_{k}^{D L}\right)^{H}+\triangle_{k}^{D L}\right| \\
& -\left(\log \left|\triangle_{k}^{D L(n)}\right|+\left\langle\left(\triangle_{k}^{D L(n)}\right)^{-1}\left(\triangle_{k}^{D L}-\triangle_{k}^{D L(n)}\right)\right\rangle\right)
\end{aligned}
$$

$$
\begin{aligned}
& \widetilde{R}_{k}^{U L}=\log \left|H_{k}^{U L} Q_{k}^{U L}\left(H_{k}^{U L}\right)^{H}+\triangle_{k}^{U L}\right| \\
& -\left(\log \left|\triangle_{k}^{U L(n)}\right|+\left\langle\left(\triangle_{k}^{U L(n)}\right)^{-1}\left(\triangle_{k}^{U L}-\triangle_{k}^{U L(n)}\right)\right\rangle\right)
\end{aligned}
$$

Similarly, constraints (18), (19) are upper bounded by convex functions respectively defined as

$$
\begin{aligned}
& \log \left|\Gamma_{i}^{(n)}+\Xi_{i}^{D L(n)}\right|+ \\
& \left\langle\left(\Gamma_{i}^{(n)}+\Xi_{i}^{D L(n)}\right)^{-1}\left(\Gamma_{\mathrm{i}}-\Gamma_{\mathrm{i}}^{(\mathrm{n})}\right)\right\rangle+ \\
& +\left\langle\left(\Gamma_{i}^{(n)}+\Xi_{i}^{D L(n)}\right)^{-1}\left(\Xi_{\mathrm{i}}^{\mathrm{DL}}-\Xi_{\mathrm{i}}^{\mathrm{DL}(\mathrm{n})}\right)\right\rangle \\
& -\log \left|\Xi_{i}^{D L}\right| \leq C_{i}^{D L}, i \in S^{R U},
\end{aligned}
$$

and

$$
\begin{aligned}
& \log \left|\phi_{i}^{U L}+\Xi_{i}^{U L(n)}\right|+ \\
& \left\langle\left(\phi_{i}^{U L}+\Xi_{i}^{U L(n)}\right)^{-1}\left(\phi_{i}^{U L}-\phi_{i}^{U L(n)}\right)\right\rangle+ \\
& \left\langle\left(\phi_{i}^{U L}+\Xi_{i}^{U L(n)}\right)^{-1}\left(\Xi_{i}^{U L}-\Xi_{i}^{U L(n)}\right)\right\rangle \\
& -\log \left|\Xi_{i}^{D L}\right| \leq C_{i}^{D L}, i \in S^{R U},
\end{aligned}
$$

where

$$
\Gamma_{i}=\gamma_{i}^{H} \sum_{k=1}^{K_{D L}} Q_{k}^{D L} \gamma_{i}
$$

Then, problem (27) can be cast as

$$
\begin{gathered}
\max _{\{Q, \Xi\}}=\frac{\sum_{k=1}^{K_{D L}} \widetilde{R}_{k}^{D L}+\sum_{k=1}^{K_{U L}} \widetilde{R}_{k}^{U L}}{P} \\
\text { s.t. }(25),(26),(27 c),(27 d),(30),(31)
\end{gathered}
$$

It is obvious that the denominator in (33a) is linear while the numerator is concave in matrix variables Q. Thus, problem (33) is known as a concave-convex fractional programming and, then, the Dinkelbach approach $^{24,37,38}$ can be efficiently used to find optimal solutions. Accordingly, a parameter $\lambda$ and a parametric function $U=\sum_{k=1}^{K_{D L}} \widetilde{R}_{k}^{D L}+\sum_{k=1}^{K_{U L}} \widetilde{R}_{k}^{U L}-\lambda P$ are introduced. Problem (33) can be rewritten as

$$
\max _{\{Q, \Xi\}} \mathrm{U}
$$

$$
\text { s.t. }(25),(26),(27 c),(27 d),(30),(31)
$$

Note that OP (34) is convex for fixed $\lambda$, and convex solvers, e.g., $\mathrm{CVX}^{39}$ can be efficiently used to find the optimal solutions to OP (34). The detailed algorithm to find the covariance matrices to maximize the FD CRAN EE is summarized in Algorithm 1.

\section{Algorithm 1: Iterative algorithm for EE maximiza-} tion

Initialize: Let $n=0$ and choose a feasible point $Q^{(0)}, \widetilde{Q}^{(0)}$ and the quantization noise covariance matrices $\Xi^{(0)}, \widetilde{\Xi}^{(0)}$.

repeat

repeat

Compute $\lambda^{(n)}$ by plugging $Q^{(n)}$ and $\Xi^{(n)}$ to $\frac{\sum_{k=1}^{K_{D L}} \widetilde{R}_{k}^{D L}+\sum_{k=1}^{K_{U L}} \widetilde{R}_{k}^{U L}}{P}$

Given $\lambda^{(n)}, Q^{(n)}$ and $\Xi^{(n)}$, solve (34) using CVX to obtain $Q^{*}$ and $\lambda^{*}$

Update $Q^{(n)}=Q^{*}$ and $\Xi^{(n)}=\Xi^{*}$

until convergence

Update $n=n+1$ update $\widetilde{Q}^{(n)}=Q^{(n)}$ and $\widetilde{\Xi}^{(\mathrm{n})}=\Xi^{(n)}$

until convergence

Output: $Q^{o p t}, \Xi^{o p t}$

\section{RESULTS AND DISCUSSION}

In this section, we simulate a FD CRAN system with the following parameters: $K_{R}=4, M_{k}=N_{k}=2, \forall k \in$ $S^{R U}, K_{D L}=K_{U L}=4$ and $T_{k}=R_{k}=2, \forall k$. Moreover, we assume that the same TP constraints, i.e., $P_{i}^{D L}=P^{D L}, i \in S^{R U}$ are imposed on RUs and UL users, and $P_{i}^{U L}=P^{U L}=0.7 \times P^{D L}$ with $k \in S^{U L}$. The noise powers in both UL and DL channels are set to $\sigma_{D L}^{2}=\sigma_{U L}^{2}=-107 \mathrm{dBm}$. Both UL and DL channels are assumed to have the same $\mathrm{FH}$ rate constraints for all RUs, i.e., $C_{i}^{X}=C_{F H}\left(10^{7} \mathrm{bps}\right), \forall i \in S^{R U}, X \in$ $\{U L, D L\}$, the bandwidth of the wireless system is 10 $\mathrm{MHz}$, and the circuit power consumed by a RU and UE are $P_{U E}=0.1 \mathrm{~W}, P_{R U}=10.65 \mathrm{~W}$, respectively ${ }^{35}$. The users are randomly distributed in a square area of side length $100 \mathrm{~m}$. The square is divided into four equal small squares with a side length $50 \mathrm{~m}$. RUs are 
at the center of these small squares. We adopt the SI channel model in which the SI channel $H_{i i}^{U D}$ at $R U_{i}$ is distributed as Rician with mean $\sqrt{\sigma_{S I}^{2} \kappa(1-\kappa)^{-1}}$ and variance $\sigma_{S I}^{2} \kappa(1+\kappa)^{-140}$, where $\kappa$ and $\sigma_{S I}^{2}$ are the Rician factor and the residual SI power, respectively. In this simulation, we set $\kappa=10$. The other channel matrices follow complex Gaussian distributions with path loss at distance $d(\mathrm{~m})$ defined as $P L=$ $22.9+37.5 \log _{10} d$ in $\mathrm{dB}^{18,19}$. We conduct 100 Monte Carlo runs with random locations of users to compute the average of the numerical results in simulations. For comparison between the FD and HD CRAN models, we consider the EE OPs of the HD CRAN as

$$
\begin{gathered}
\max _{\{Q, \Xi\}} \frac{0.5\left(\bar{R}_{\text {sum }}^{D L}+\bar{R}_{\text {sum }}^{U L}\right)}{P} \\
\text { s.t. }(25),(26),(27 c),(27 d),(30),(31)
\end{gathered}
$$

where $\bar{R}_{\text {sum }}^{D L}$ and $\bar{R}_{\text {sum }}^{U L}$ are the achievable DL and UL rate in the HD scheme, respectively. The factor of 0:5 in (35a) is due to the fact that the DL and UL transmissions share half of the time and/or frequency resource. It also notes that all SI channels $\left\{H^{U D}\right\}$ and CCI channels are set to 0 in HD mode.

Example 1: This example investigates the convergence behaviours of Algorithm 1. Figure 2 depicts the convergence rate of the EE functions under different values of $\sigma_{S I}^{2}$. It is obvious that the EE functions are not decreasing over iterations and converged within about 40 iterations. The results from Figure 2 also show that the achievable EE tends to increase when the residual SI value decreases.

Example 2: The achievable EE and SR over different TP budgets are evaluated. In this example, we set $C_{F H}=10^{8}$ bps. The achievable EE and SR are illustrated in Figure 3 and Figure 4, respectively. As expected, the higher EE performance is achieved at higher TP budgets. On the other hand, in these simulation settings, the EE obtained in FD transmission is higher than that in the HD counterpart. In addition, when a certain level of TP is reached, the resulting EE performance is saturated. Thus, these results can give useful information to set the appropriate $\mathrm{TP}$ at the transmitters. To provide more information about the achievable SR of the EE optimization Algorithm 1, the achievable SRs are plotted in Figure 4. It can be observed from Figure 4 that the achievable SRs in the considered settings are superior to that of the HD schemes. The smaller SI in FD transmission can lead to its better SR improvement.
Example 3: The EE and SR over different FH capacity limitations are investigated in this example. In this example, the TP budgets of the RUs are set $25 \mathrm{dBm}$. The average achievable EE is depicted in Figure 5 while the average achievable SR is shown in Figure 6. From the two figures, we can see that both achievable EE and SR are improved when the FH capacity increases. Noting that when the FH capacity is low, it is a bottleneck to restrict the system performance. In such cases, to reduce the FH traffic, the system will switch to a single RU association ${ }^{19}$. Therefore, when the FH capacity increases, the achievable EE and SR are increased. On the other hand, the achievable EE and SR increase as SI decreases.

\section{CONCLUSION}

In this paper, a joint design of $\mathrm{FH}$ compression and precoding has been studied for a FD MIMO CRAN. We have addressed the EE maximization problem for this considered system model by developing the IA using successive convex approximation and Dinkelbach approaches to deal with the non-convex problem. Finally, by numerical simulation results, we have shown that the considered FD CRAN system can bring significant EE gains over the HD scheme when SI is low. In addition, the results have unveiled the interesting influence of $\mathrm{FH}$ rate levels on the system EE performance. Particularly, the bottleneck situation caused by the limited FH capacity leads to the degradation in the EE system performance.

\section{ACKNOWLEDGMENT}

This research is funded by Vietnam National Foundation for Science and Technology Development (NAFOSTED) under grant number 102.04-2017.308.

\section{LIST OF ABBREVIATIONS}

CRAN: xloud radio access network

CU: control unit

D.C.: difference of convex

DL: downlink

EE: energy efficiency

FD: full-duplex

FH: fronthaul

HD: half-duplex

IA: iterative algorithm

MIMO: multiple-input multiple-output

MISO: multiple-input single-output

OP: optimization problem

QoS: quality-of-service

RA: receive antenna

$\mathrm{RU}$ : radio unit 


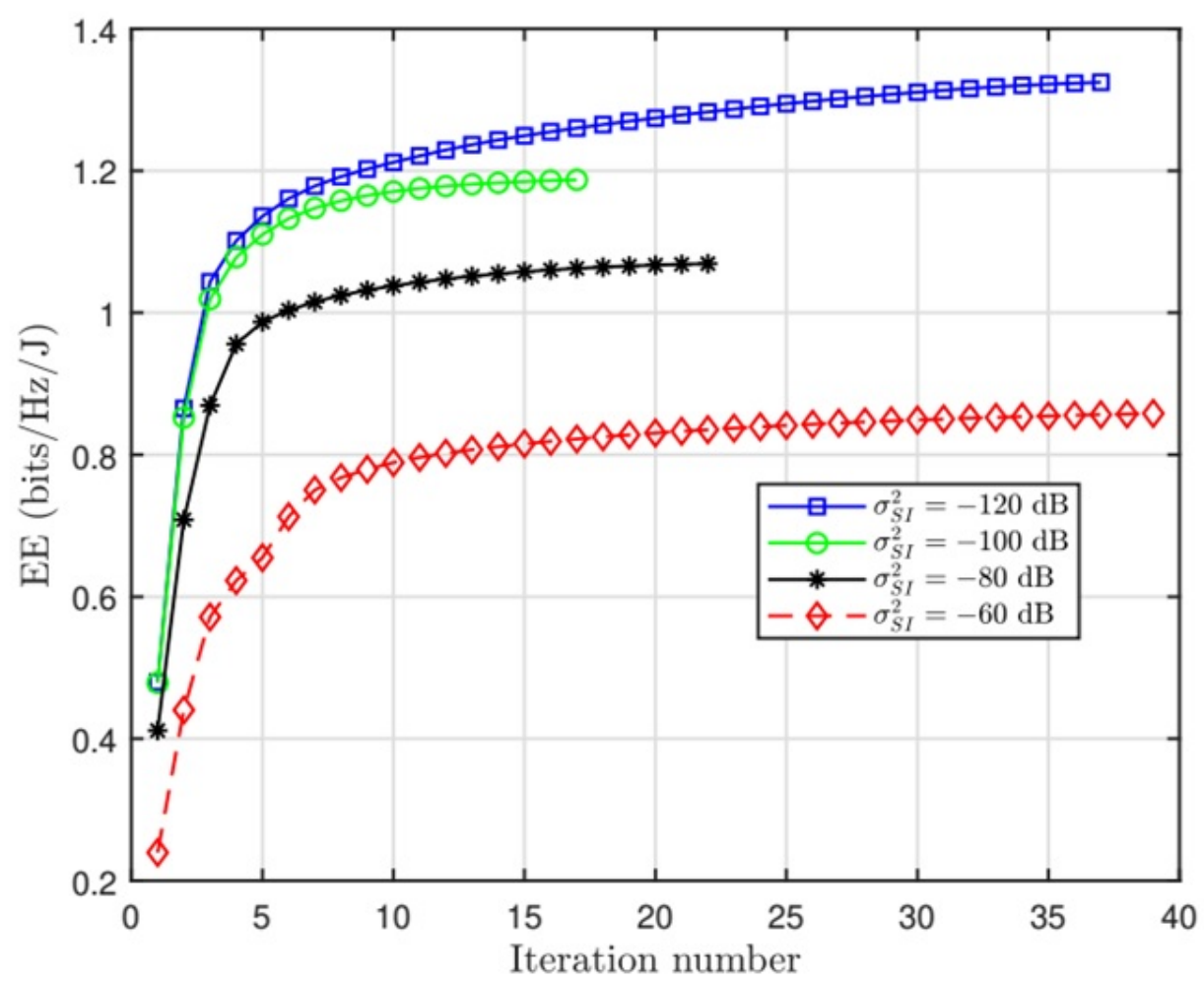

Figure 2: Convergence behaviors of our IA for different levels of residual SI.

SE: spectral efficiency

SI: self-interference

SR: sum-rate

TA: transmit antenna

TP: transmit power

UE: user equipment

UL: uplink

\section{CONFLICT OF INTEREST}

The authors declare that there is no conflict of interest regarding the publication of this article.

\section{AUTHORS' CONTRIBUTIONS}

All the authors contribute equally to the paper including the research idea and written manuscript.

\section{REFERENCES}

1. Singh K, Gupta A, Ratnarajah T, Ku M. A general approach toward green resource allocation in relay-assisted multiuser communication networks," IEEE Trans. Wireless Commun. 2018;17(2):848-862. Available from: https://doi.org/10.1109/ TWC.2017.2772229.

2. Peng M, Sun Y, Li X, Mao Z, Wang C. Recent advances in cloud radio access networks: System architectures, key techniques, and open issues. IEEE Commun. Surv. Tut. 2016;18(3):22822308. Available from: https://doi.org/10.1109/COMST.2016. 2548658.
3. Luong P, Gagnon F, Despins C, Tran L. Optimal joint remote radio head selection and beamforming design for limited fronthaul CRAN. IEEE Trans. Signal Process. 2017;65(21):56055620. Available from: https://doi.org/10.1109/TSP.2017. 2739102.

4. Lee S, Park S, Lee I. NOMA systems with content-centric multicast transmission for C-RAN. IEEE Wireless Commun. Lett. 2018;7(5):828-831. Available from: https://doi.org/10.1109/ LWC.2018.2829514.

5. Kim J, Lee H, Park S, Lee I. Minimum rate maximization for wireless powered cloud radio access networks. IEEE Trans. Veh. Technol. 2019;68(1):1045-1049. Available from: https://doi. org/10.1109/TVT.2018.2881969.

6. Kim J, Park S, Simeone O, Lee I, Shitz SS. Joint design of fronthauling and hybrid beamforming for downlink C-RAN systems. IEEE Trans. Commun. 2019;67(6):4423-4434. Available from: https://doi.org/10.1109/TCOMM.2019.2903142.

7. Yu D, Kim J, Park S. An efficient rate-splitting multiple ac cess scheme for the downlink of C-RAN systems. IEEE Wireless Commun Lett. 2019;8(6):1555-1558. Available from: https: //doi.org/10.1109/LWC.2019.2927206.

8. Park S, Simeone O, Sahin O, Shamai S. Joint precoding and multivariate backhaul compression for the downlink of cloud radio access networks. IEEE Trans. Signal Process. 2013;61(22):5646-5658. Available from: https://doi.org/10. 1109/TSP.2013.2280111.

9. Robust and efficient distributed compression for cloud radio access networks. IEEE Trans. Veh. Technol. 2013;62(2):692703. Available from: https://doi.org/10.1109/TVT.2012. 2226945.

10. Inter-cluster design of precoding and fronthaul compression for cloud radio access networks. IEEE Wireless Commun. Lett. 


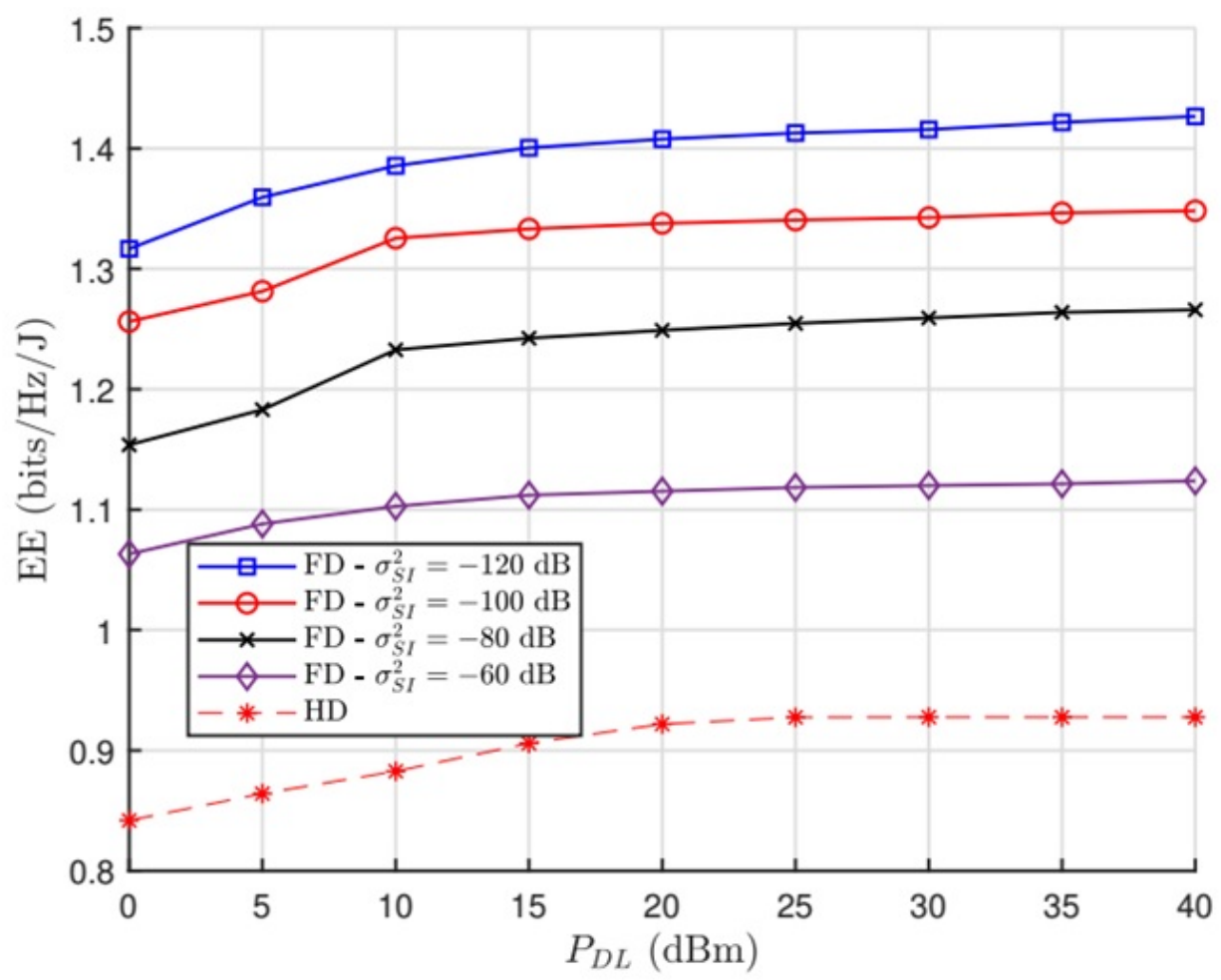

Figure 3: The average achievable EE versus different TP budgets.

2014;3(4):369-372. Available from: https://doi.org/10.1109/ LWC.2014.2317735.

11. Zhang Z, Long K, Vasilakos AV, Hanzo L. Full-duplex wireless communications: Challenges, solutions, and future research directions. Proc. IEEE. 2016;104(7):1369-1409. Available from: https://doi.org/10.1109/JPROC.2015.2497203.

12. Sheng Z, Tuan HD, Tam HHM, Nguyen H. Energy efficient precoding in multicell networks with full-duplex base stations. EURASIP J. Wireless Commun. Network. 2017;48. Available from: https://doi.org/10.1186/s13638-017-0831-5.

13. Nguyen V, Duong TQ, Tuan HD, Shin O, Poor HV. Spectral and energy efficiencies in full-duplex wireless information and power transfer. IEEE Trans. Commun. 2017;65(5):22202233. Available from: https://doi.org/10.1109/TCOMM.2017. 2665488.

14. Vu TT, Ngo DT, Ngo HQ, Le-Ngoc T. Full-duplex cell-free massive MIMO. in ICC 2019 - 2019 IEEE Int. Conf. Commun. (ICC). 2019;p. 1-6.

15. Huberman S, Le-Ngoc T. Full-duplex MIMO precoding for sumrate maximization with sequential convex programming. IEEE Trans. Veh. Technol. 2015;64(11):5103-5112. Available from: https://doi.org/10.1109/TVT.2014.2380775.

16. Simeone O, Erkip E, Shamai S. Full-duplex cloud radio access networks: An information-theoretic viewpoint. IEEE Wireless Commun. Lett. 2014;3(4):413-416. Available from: https://doi. org/10.1109/LWC.2014.2323073.

17. Zhao $M$, Shi $Q$, Cai $Y$, Zhao $M$. Joint transceiver design for fullduplex cloud radio access networks with SWIPT. IEEE Trans. Wireless Commun. 2017;16(9):5644-5658. Available from: https://doi.org/10.1109/TWC.2017.2712693.

18. Jeon $Y$, et al. Joint designs of fronthaul compression and precoding for full-duplex cloud radio access networks. IEEE
Wireless Commun. Lett. 2016;5(6):632-635. Available from: https://doi.org/10.1109/LWC.2016.2609410.

19. Cirik $A C$, et al. Fronthaul compression and precoding design for full-duplex cloud radio access network. IEEE Syst. J. 2019;13(2):1113-1124. Available from: https://doi.org/10. 1109/JSYST.2019.2900996.

20. Tang W, Feng S. User selection and power minimization in fullduplex cloud radio access networks. IEEE Trans. Signal Process. 2019;67(9):2426-2438. Available from: https://doi.org/ 10.1109/TSP.2019.2905804.

21. Fang C, Li P, Feng K. Joint interference cancellation and resource allocation for full-duplex cloud radio access networks. IEEE Trans. Wireless Commun. 2019;18(6):3019-3033. Available from: https://doi.org/10.1109/TWC.2019.2908173.

22. Buzzi $S$, et al. A survey of energy-efficient techniques for $5 G$ networks and challenges ahead. IEEE J. Sel. Areas Commun. 2016;34(4):697-709. Available from: https://doi.org/10.1109/ JSAC.2016.2550338.

23. Sheng $Z$, et al. Power allocation for energy efficiency and secrecy of wireless interference networks. IEEE Trans. Wireless Commun. 2018;17(6):3737-3751. Available from: https: //doi.org/10.1109/TWC.2018.2815626.

24. Nguyen $\mathrm{X}, \mathrm{Kha} \mathrm{HH}$. Energy efficient full-duplex multicell multiuser MIMO networks. in 2018 Int. Conf. Advan. Technol. Commun. (ATC). 2018;p. 163-167. Available from: https://doi.org/ 10.1109/ATC.2018.8587433.

25. Shi Y, Zhang J, Letaief KB. Group sparse beamforming for green Cloud-RAN. IEEE Trans. Wireless Commun 2014;13(5):2809-2823. Available from: https://doi.org/10. 1109/TWC.2014.040214.131770.

26. Dai B, Yu W. Energy efficiency of downlink transmission strategies for cloud radio access networks. IEEE J. Sel. Areas Com- 


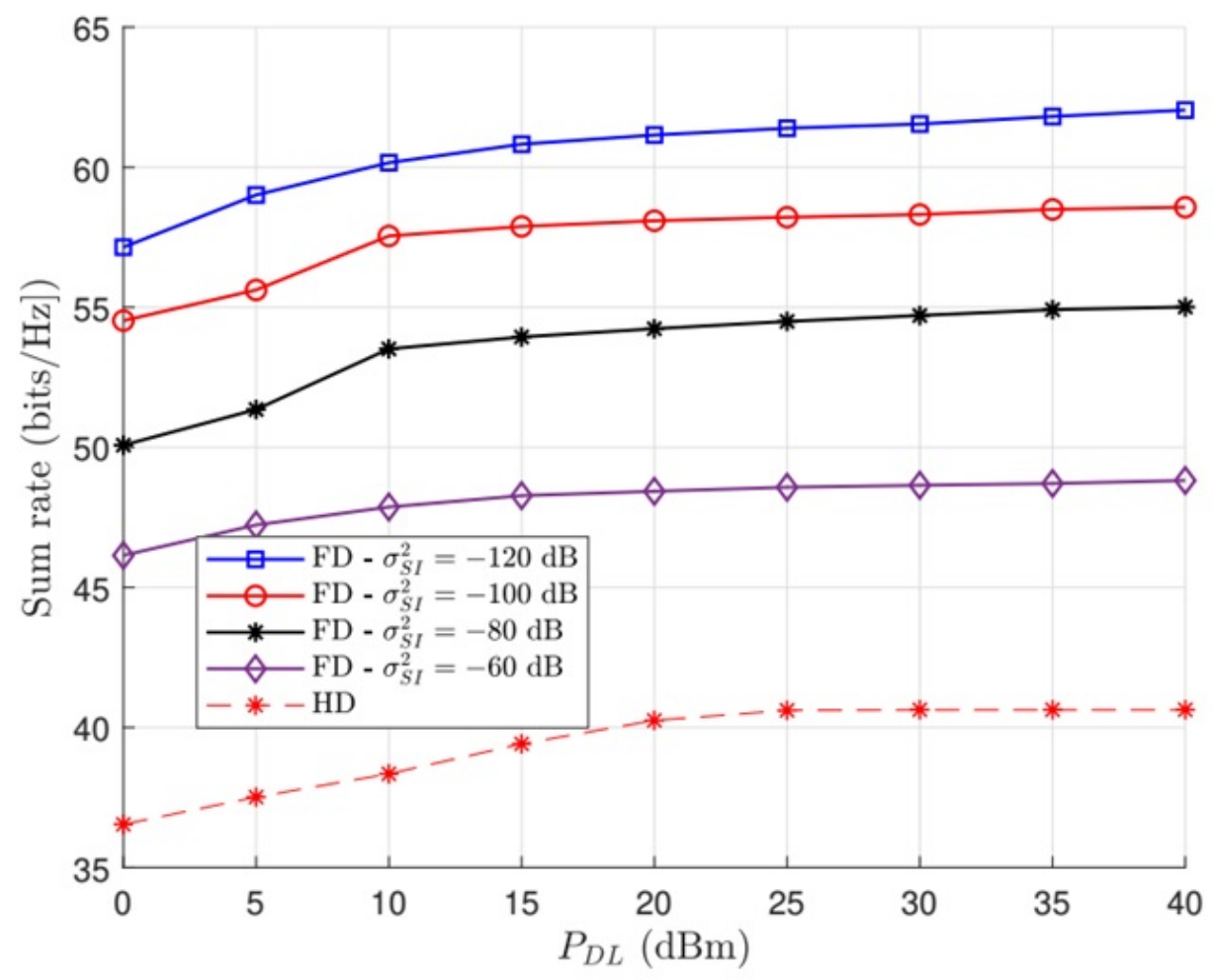

Figure 4: The average achievable SR versus different TP budgets.

mun. 2016;34(4):1037-1050. Available from: https://doi.org/ 10.1109/JSAC.2016.2544459.

27. $\mathrm{Vu} \mathrm{TT}$, et al. Energy efficiency maximization for downlink cloud radio access networks with data sharing and data compression," IEEE Trans. Wireless Commun. 2018;17(8):49554970. Available from: https://doi.org/10.1109/TWC.2018. 2834370.

28. Vu TT, et al. Spectral and energy efficiency maximization for content-centric CRANs with edge caching. IEEE Trans. Commun. 2018;66(12):6628-6642. Available from: https://doi.org/ 10.1109/TCOMM.2018.2866458.

29. Nguyen $K, V u$ Q, Juntti M, Tran L. Energy efficiency maximization for C-RANs: Discrete monotonic optimization, penalty, and '0- approximation methods. IEEE Trans Signal Process. 2018;66(17):4435-4449. Available from: https://doi.org/10. 1109/TSP.2018.2849746.

30. Luong P, Gagnon F, Despins C, Tran L. Joint virtual computing and radio resource allocation in limited fronthaul green C-RANs. IEEE Trans. Wireless Commun. 2018;17(4):2602-2617. Available from: https://doi.org/10.1109/TWC.2018.2799859.

31. Optimal energy-efficient beamforming designs for CloudRANs with rate-dependent fronthaul power. IEEE Trans. Commun. 2019;67(7):5099-5113. Available from: https://doi.org/ 10.1109/TCOMM.2019.2906590.

32. Vu TT, et al. Energy-efficient full-duplex enabled cloud radio access networks. IEICE Trans. Commun. 2020;E103.B(1):7178. Available from: https://doi.org/10.1587/transcom. 2018EBP3327.

33. Shi L, Zhao L, Liang K. Power allocation for wireless powered MIMO transmissions with non-linear RF energy conver- sion models. China Commun. 2017;14(2):57-64. Available from: https://doi.org/10.1109/CC.2017.7868175.

34. Zhou Y, Yu W. Fronthaul compression and transmit beamforming optimization for multi-antenna uplink C-RAN. IEEE Trans. Signal Process. 2016;64(16):4138-4151. Available from: https://doi.org/10.1109/TSP.2016.2563388.

35. Nguyen K, Vu Q, Tran L, Juntti M. Globally optimal energy efficiency maximization for capacity-limited fronthaul CRANS with dynamic power amplifiers efficiency. in 2018 IEEE Int. Conf. Acoustics, Speech and Signal Process. (ICASSP). 2018;p. 3759-3763. Available from: https://doi.org/10.1109/ICASSP. 2018.8461308.

36. Kha HH, Tuan HD, Nguyen HH. Fast global optimal power allocation in wireless networks by local D.C. programming. IEEE Trans. Wireless Commun. 2012;11(2):510-515. Available from: https://doi.org/10.1109/TWC.2011.120911.110139.

37. Crouzeix J, Ferland J. Algorithms for generalized fractional programming. Mathematical Programming. 1991;52(1):191207. Available from: https://doi.org/10.1007/BF01582887.

38. Pham VQ, Ha TN, Kha HH, Quyet PV. Energy efficiency maximization with per-antenna power constraints for heterogeneous networks. in 2019 Int. Sym. Electr. and Electron. Eng. (ISEE). 2019;p. 1-6. Available from: https://doi.org/10.1109/ ISEE2.2019.8920866.

39. Grant M, Boyd S. CVX: MATLAB software for disciplined convex programming, version 2.1. 2014;

40. Cirik AC, Wang R, Rong Y, Hua Y. MSE-based transceiver designs for full-duplex MIMO cognitive radios. IEEE Trans. Commun. 2015;63(6):2056-2070. Available from: https://doi.org/ 10.1109/TCOMM.2015.2434385. 


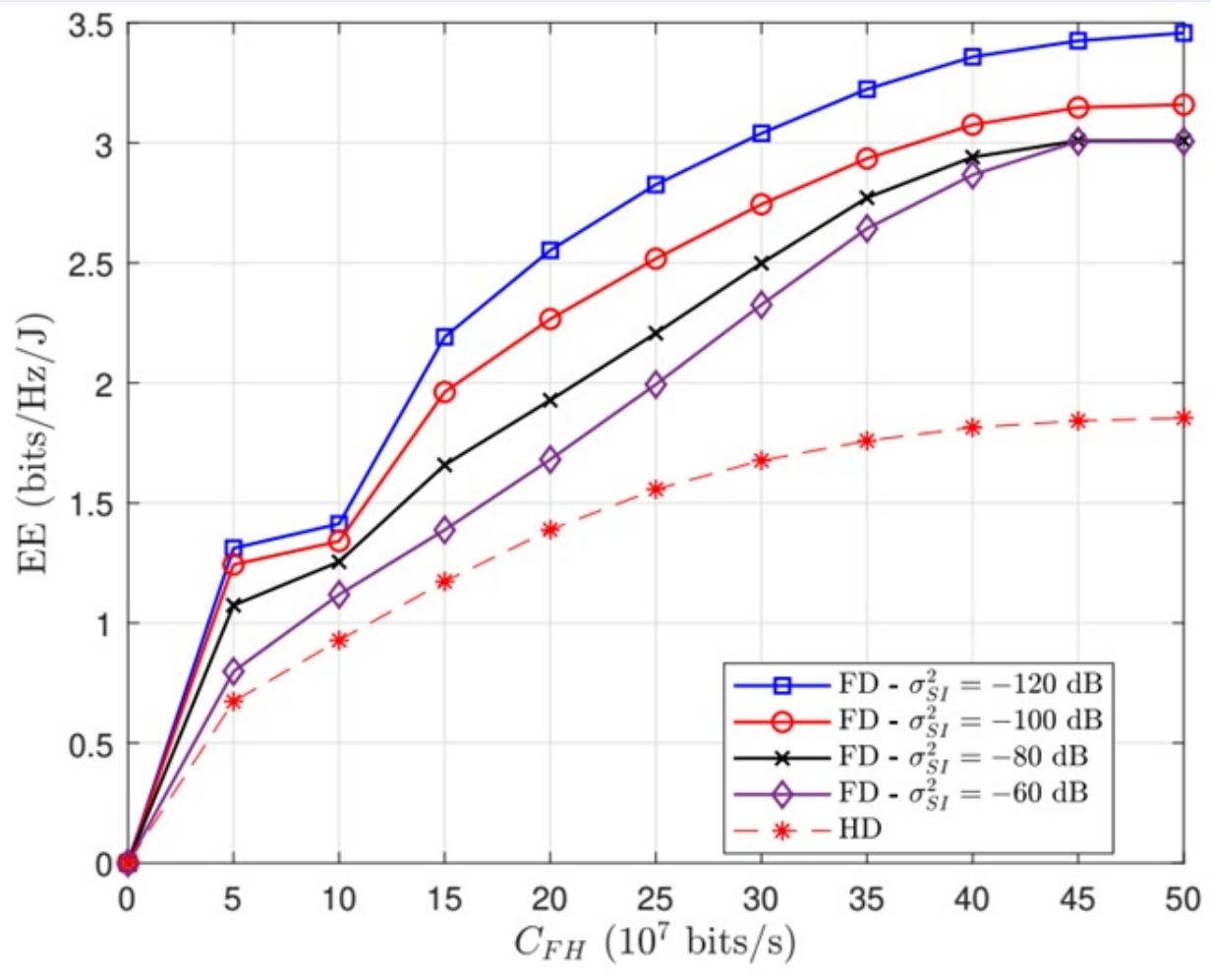

Figure 5: The average achievable EE versus different levels of $C_{F H}$.

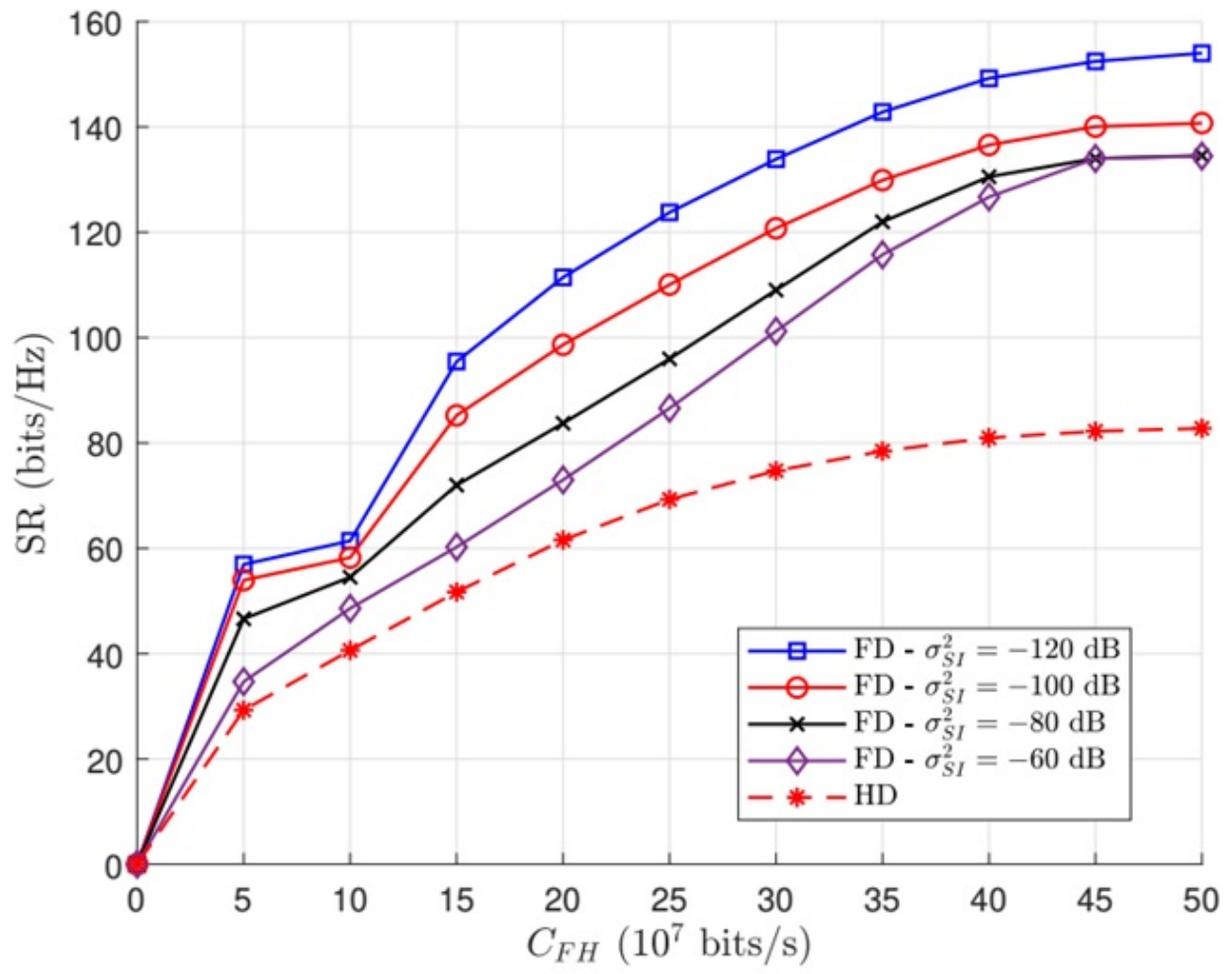

Figure 6: The average achievable SR versus different levels of $C_{F H}$. 


\title{
Cực đại hóa hiệu suất năng lượng trong hệ thống MIMO CRAN song công
}

\author{
Hà Ngọc Tiến ${ }^{1,2}$, Nguyễn Xuân Xinh ${ }^{1,2}$, Hà Hoàng Kha ${ }^{1,2, *}$
}

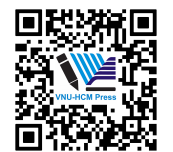

Use your smartphone to scan this QR code and download this article

${ }^{1}$ Khoa Điện-Điện tủ, Trường Đại học Bách Khoa TP.HCM, Việt Nam

${ }^{2} Đ a ̣ i$ học Quốc gia Thành phố Hồ Chí Minh

Liên hệ

Hà Hoàng Kha, Khoa Điện-Điện tử, Trường Đại học Bách Khoa TP.HCM, Việt Nam

Đại học Quốc gia Thành phố Hồ Chí Minh

Email: hhkha@hcmut.edu.vn

Lịch sử

- Ngày nhận: 17-3-2020

- Ngày chấp nhận: 4-12-2020

- Ngày đăng: 20-12-2020

DOI : 10.32508/stdjet.v3i3.685

\section{Check for updates}

\section{Bản quyền}

๑) ĐHQG Tp.HCM. Đây là bài báo công bố mở được phát hành theo các điều khoản của the Creative Commons Attribution 4.0

International license.

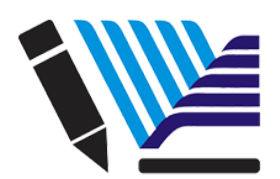

VNU-HCM Press

\section{TÓM TẮT}

Bài báo này nghiên cứu hiệu quả năng lượng của hệ thống MIMO CRAN song công. Một trạm điều khiển trung tâm (CU) truyền tín hiệu thồng tin với các thiết bị người dùng đường lên và đường xuống thông qua các trạm vô tuyến RU song công bằng các đường liên kết $\mathrm{FH}$ có dung lượng giới hạn. Trong kênh truyền đường xuống, các tín hiệu mong muốn phát cho người dùng đường xuống được xử lý tập trung ở trạm điều khiển trung tâm và sau đó được nén để truyền đến các trạm vô tuyến RU trước khi chúng được chuyển tiếp đến người dùng đường xuống. Mặc khác, các tín hiệu từ người dung đường lên đến các trạm vô tuyến được nén và chuyển đến trạm điều khiển trung tâm cho việc xử lý giải mã tín hiệu. Do đó, việc thiết kế tiền mã hóa và chiến lược nén cho truyền đường lên và đường xuống là quan trong đối với hiệu năng hệ thống. Các phương pháp phổ biến là tập trung tối đa hóa hiệu suất phổ trong mạng. Mặc dù các phương pháp dựa trên cực đại hóa hiệu suất phổ có thể cung cấp hiệu suất phổ tốt, chúng có thể dẫn đến việc sử dụng nằng lượng không hiệu quả. Do đó, bài báo này tập trung thiết kể đồng thời bộ tiền mã hóa và các ma trận hiệp phương sai lượng tử để tối đa hóa hiệu suất năng lượng. Vấn để tối đa hóa hiệu suất năng lượng được biểu diễn như một bài toán tối ưu của các ma trận tiên mã hóa và ma trần hiệu phương sai lượng tử phụ thuộc vào điều kiện ràng buộc công suất phát ở mỗi trạm vô tuyến, mỗi người dùng và dung lượng giới hạn của các liên kểt FH. Để giải quyết vấn để không lồi của bài toán thiết kế, chúng tôi khai thác phương pháp xấp xỉ lôi tuần tự để rút ra hàm biên dưới lõm của tổng tốc độ kênh và biên trên lồi của dung lượng đường liên kế FH. Sau đó, giải thuật Dinkelbach được khai thác để phát triển giải thuật lặp hiệu quả đảm bảo tính hội tụ. Các kết quả mô phỏng số được thực hiện để minh họa hiệu suất năng lượng EE của giải thuật.

Từ khoá: Song công, CRAN, thiết kế tiền mã hóa, hiệu suất năng lượng
Trích dẫn bài báo này: Tiến $\mathrm{H} \mathrm{N}$, Xinh $\mathrm{N} \mathrm{X}$, Kha H H. Cực đại hóa hiệu suất năng lượng trong hệ thống MIMO CRAN song công. Sci. Tech. Dev. J. - Eng. Tech.; 3(3):488-499. 